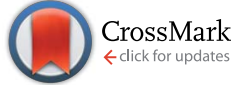

Cite this: J. Mater. Chem. A, 2016, 4, 11604

Received 5th May 2016 Accepted 1st July 2016

DOI: $10.1039 / c 6 t a 03755 k$

www.rsc.org/MaterialsA

\section{Extending the environmental lifetime of unpackaged perovskite solar cells through interfacial design $\uparrow$}

\author{
Haiwei Chen, $t^{* a}$ Yi Hou, $t^{\text {ab }}$ Christian E. Halbig, de Shi Chen, ${ }^{* a}$ Hong Zhang, ${ }^{\text {ab }}$ Ning Li, ${ }^{a}$ \\ Fei Guo, ${ }^{\text {a } X i a o f e n g ~ T a n g,}$, Nicola Gasparini, ${ }^{a}$ levgen Levchuk, ${ }^{\text {a }}$ Simon Kahmann, af \\ Cesar Omar Ramirez Quiroz, ${ }^{a}$ Andres Osvet, ${ }^{a}$ Siegfried Eigler ${ }^{\text {deg }}$ \\ and Christoph J. Brabec ${ }^{\star a c}$
}

Solution-processed oxo-functionalized graphene (oxo- $G_{1}$ ) is employed to substitute hydrophilic PEDOT:PSS as an anode interfacial layer for perovskite solar cells. The resulting devices exhibit a reasonably high power conversion efficiency (PCE) of $15.2 \%$ in the planar inverted architecture with oxo- $G_{1}$ as a hole transporting material (HTM), and most importantly, deploy the full open-circuit voltage $\left(V_{\text {oc }}\right)$ of up to $1.1 \mathrm{~V}$. Moreover, oxo- $\mathrm{G}_{1}$ effectively slows down the ingress of water vapor into the device stack resulting in significantly enhanced environmental stability of unpackaged cells under illumination with $80 \%$ of the initial PCE being reached after $500 \mathrm{~h}$. Without encapsulation, $\sim 60 \%$ of the initial PCE is retained after $\sim 1000 \mathrm{~h}$ of light soaking under 0.5 sun and ambient conditions maintaining the temperature beneath $30{ }^{\circ} \mathrm{C}$. Moreover, the unsealed perovskite device retains $92 \%$ of its initial PCE after about $1900 \mathrm{~h}$ under ambient conditions and in the dark. Our results underpin that controlling water diffusion into perovskite cells through advanced interface engineering is a crucial step towards prolonged environmental stability.

Perovskite solar cells have attracted considerable research interest due to their remarkable PCEs exceeding the $20 \%$

${ }^{a}$ Institute of Materials for Electronics and Energy Technology (I-MEET), Department of Materials Science and Engineering, Friedrich-Alexander University Erlangen-Nuremberg, Martensstrasse 7, 91058 Erlangen, Germany. E-mail: haiwei. chen@fau.de; shi.chen@fau.de; xiaofeng.tang@fau.de; christoph.brabec@fau.de ${ }^{b}$ Erlangen Graduate School in Advanced Optical Technologies (SAOT), Paul-GordanStr. 6, 91052 Erlangen, Germany

${ }^{\circ}$ Bavarian Center for Applied Energy Research (ZAE Bayern), Am Weichselgarten 7, 91058 Erlangen, Germany

${ }^{d}$ Department of Chemistry and Pharmacy, University Erlangen-Nürnberg (FAU), Henkestraße 42, 91052 Erlangen, Germany

${ }^{e}$ Institute of Advanced Materials and Processes (ZMP), Dr. Mack Straße. 81, 90762 Fürth, Germany

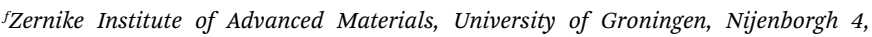
9747AG Groningen, The Netherlands

${ }^{g}$ Department of Chemistry and Chemical Engineering, Chalmers University of Technology, Kemivägen 10, 41258 Göteborg, Sweden

$\dagger$ Electronic supplementary information (ESI) available. See DOI: 10.1039/c6ta03755k

$\$$ These authors contributed equally to this work. benchmark and their potential to be manufactured by low-cost solution-processing technologies. ${ }^{1-3}$ Device operational lifetime is the third corner of the magic triangle evaluating the performance potential of photovoltaic technologies, and this is of particular concern for the perovskite-based technology owing to its water soluble Pb-salt component. ${ }^{4,5}$ Limited shelf as well as operational lifetime have been reported in the early stages of perovskite research and appeared to be one of the major roadblocks towards further driving this technology. ${ }^{6}$ The precise degradation mechanism of perovskites in the presence of water is still under discussion. Previous studies have reported the loss of methyl-amine and the formation of yellowish $\mathrm{PbI}_{2}$, while more recent studies rather suggest the partially reversible formation of $\left(\mathrm{CH}_{3} \mathrm{NH}_{3}\right)_{4} \mathrm{PbI}_{6}: \mathrm{H}_{2} \mathrm{O}$ hydrate complexes as an intermediate step. ${ }^{7,8}$ In addition, oxygen has been found to have only little effect on the degradation of perovskite devices. ${ }^{8}$

To address the stability issue of the perovskite solar cells, many efforts have recently been made. For example, several photo- or moisture-stable perovskite materials such as $\left(\mathrm{C}_{6} \mathrm{H}_{5}\right.$ $\left.\left(\mathrm{CH}_{2}\right)_{2} \mathrm{NH}_{3}\right)_{2}\left(\mathrm{CH}_{3} \mathrm{NH}_{3}\right)_{2}\left[\mathrm{~Pb}_{3} \mathrm{I}_{10}\right], \mathrm{FA}_{1-x} \mathrm{Cs}_{x} \mathrm{PbI}_{3}$ and $\left(\mathrm{CH}_{3} \mathrm{NH}_{3}-\right.$ $\left.\mathrm{Pb}(\mathrm{SCN})_{2}\right)$ have been developed. ${ }^{9-11}$ Recently, it has also been suggested that cross-linking perovskite grains with phosphonic acid ammonium derivatives may further decrease the moisture sensitivity of perovskite devices. ${ }^{12}$

A technically straightforward possibility to guarantee longliving perovskite devices is to provide a water and humidity dense package by using barriers and adhesives with a low water vapor transmission rate (WVTR). ${ }^{\mathbf{1 3 4}}$ Hydrophobic carbon nanotubes/poly(methyl methacrylate) composites and Teflon have been used as effective barriers to slow down the ingress of moisture and the extended lifetime of perovskite cells are observed..$^{13}$ In 2014, Han et al. employed a carbon layer as a back contact and a water-retaining layer for HTM-free perovskite solar cells. The resulting device exhibited a certified PCE of $12.8 \%$ and excellent stability under light soaking. ${ }^{15}$ In another study by Wei et al., a free-standing flexible carbon film was employed as the cathode of HTM-free perovskite solar cells, obtaining a PCE of up to $13.53 \%$ and good device stability. ${ }^{16} \mathrm{Li}$ 
et al. also demonstrated that HTM-free perovskite solar cells can withstand elevated temperature and constant outdoor illumination. ${ }^{17}$

Perovskite solar cells can be processed in various architectures such as planar structures and mesoporous structures. ${ }^{18-21}$ As our focus is on low temperature and solution-processing compatible architectures, we selected the inverted planar architecture $(\mathrm{p}-\mathrm{i}-\mathrm{n})$ for our studies. According to the literature, the most popular inverted planar architectures generally consist of a transparent electrode (e.g. fluorine- or indium-doped tin oxide (FTO or ITO)), a hole-transporting layer, a perovskite absorbing layer, an electron-transporting layer (typically phenyl-C61-butyric acid methyl ester (PCBM)) in combination with a buffer layer (e.g. $\mathrm{ZnO})$ and a cathode (e.g. $\mathrm{Al}$, $\mathrm{Ag}$, and $\mathrm{Au}) .^{20,22,23}$ Several conducting polymers (e.g., poly(3,4ethylenedioxythiophene):polystyrene sulphonate (PEDOT:PSS), poly(bis(4-phenyl)(2,4,6-trimethylphenyl)amine), and polythiophene) have been suggested as hole-transporting layers for perovskite devices. ${ }^{24,25}$ PEDOT:PSS is the most widely used holetransporting layer because of its prominent properties, such as low cost, excellent film-forming properties, "state of the art" ink standing time, green solvent and its proven track record for industrial-scale roll-to-roll processing. ${ }^{\mathbf{2}}$ However, PEDOT:PSS has disadvantages of being acidic and hygroscopic. Due to the fairly high equilibrium saturation concentration of water, PEDOT:PSS is prone to a quick accumulation of water in the interface layer. None of these disadvantages of PEDOT:PSS appear to be inevitable, and only recently we could demonstrate water-free PEDOT:PSS formulations that can be processed as a hole extraction interface layer on top of perovskite cells in the regular architecture $(n-i-p) .{ }^{27}$ Coming back to the hysteresis free replacements for PEDOT:PSS in the inverted architecture, various inorganic charge transporting layers, such as $\mathrm{NiO}_{x}$, CuSCN and graphene oxide have been recently investigated as alternative HTMs for perovskite solar cells. ${ }^{28-33}$ Replacing PEDOT:PSS with $\mathrm{NiO}_{x}-$ or $\mathrm{Li}^{+}$-doped $\mathrm{Ni}_{x} \mathrm{Mg}_{1-x} \mathrm{O}$, indeed, results in almost hysteresis free solar cells with improved air stability. ${ }^{\mathbf{2 8 , 3 4 , 3 5}}$ Reduced graphene oxide has been exploited as a barrier layer as well and a drop in PCE from about 10\% to $6 \%$ within $120 \mathrm{~h}$ in an ambient atmosphere was found. ${ }^{32}$ Graphene oxide and reduced graphene oxide stem from natural graphite and are produced under harsh oxidation conditions. These protocols result in a rupture of the carbon framework and it was reported that nanometer huge holes were introduced. ${ }^{36}$ In contrast to graphene oxide synthesis, a milder method was developed that largely excludes the formation of in-plane defects. ${ }^{37}$ In addition, functional groups were quantified and anionic organic sulfate ester groups were found in that graphene derivative (oxo- $\mathrm{G}_{1}$ ) with about one organosulfate on 20-

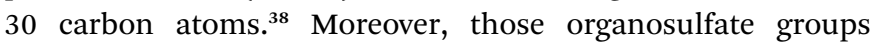
determine the negative charge of the functionalized graphene sheets. $^{38,39}$

In this work, solution-processed covalently sulfated graphene oxide (oxo- $\mathrm{G}_{1}$ ) is employed to substitute hydrophilic PEDOT:PSS as the anode interfacial layer for perovskite solar cells. The resulting devices exhibit reasonably high performance with a PCE of up to $15.2 \%$ in the planar inverted architecture with oxo-G $\mathrm{G}_{1}$ as a HTM, and most importantly, deploy the full $V_{\text {oc }}$ of up to $1.1 \mathrm{~V}$. In addition, oxo- $\mathrm{G}_{1}$ effectively slows down the ingress of water vapor into the device stack resulting in significantly enhanced environmental stability. Unpackaged cells retain $80 \%$ of their initial PCE after $500 \mathrm{~h}$ of white light illumination and approximately $60 \%$ of their initial PCE after $\sim 1000 \mathrm{~h}$ of light soaking under ambient conditions maintaining the temperature beneath $30{ }^{\circ} \mathrm{C}$. Moreover, unsealed perovskite devices can retain $92 \%$ of their initial PCE after about $1900 \mathrm{~h}$ under ambient conditions and in the dark (shelf lifetime). Our results underpin that controlling the water diffusion into perovskite cells through advanced interface engineering is a crucial step towards prolonged environmental stability.

The schematic structure of the photovoltaic devices and structural formula of the oxo- $\mathrm{G}_{1}$ are shown in Fig. 1 a. Oxo- $\mathrm{G}_{1}$ is synthesized by a wet chemical synthesis method as outlined in the literature. ${ }^{37}$ By mild oxidation, the carbon lattice is mostly preserved after oxidation and delamination in contrast to the material obtained by e.g., the Hummer's method. Additionally, organic sulphate esters bound on both sides of the single carbon sheets are not hydrolysed because the reaction temperature is permanently kept below $10{ }^{\circ} \mathrm{C}^{\mathbf{4 0}^{\mathbf{0}}}$ Subsequent statistical Raman measurements of the oxo- $\mathrm{G}_{1}$ are carried out. The defect density inside the carbon lattice is determined to be $\sim 0.8 \%$ (Fig. S1†). ${ }^{41-44}$ Fig. $1 \mathrm{~b}$ presents an AFM image of the oxo-G $\mathrm{G}_{1}$ film deposited on $\mathrm{SiO}_{2} / \mathrm{Si}$ substrate. Fig. 1c exhibits the $J-V$ characteristics of a champion device based on oxo- $\mathrm{G}_{1}$ compared to a reference device with a PEDOT:PSS interlayer. To achieve high PCE, it is necessary to realize a high $V_{\text {oc }}$ and a high short-circuit current density $\left(J_{\mathrm{sc}}\right)$ mutually. As indicated in Fig. 1c, our best performing oxo- $\mathrm{G}_{1}$-based perovskite cell shows a PCE of $15.2 \%$, a $J_{\mathrm{sc}}=18.06 \mathrm{~mA} \mathrm{~cm} \mathrm{~cm}^{-2}$, a $V_{\mathrm{oc}}=1.08 \mathrm{~V}$ and a fill factor $(\mathrm{FF})=$ $77.7 \%$, while the reference device based on PEDOT:PSS exhibits a PCE of only $10.8 \%$, with a $J_{\mathrm{sc}}=17.1 \mathrm{~mA} \mathrm{~cm}^{-2}$, a $V_{\mathrm{oc}}=0.928 \mathrm{~V}$, and a $\mathrm{FF}=68.6 \%$. The average performance of more than 30 oxo-G $\mathrm{G}_{1}$-based device peaks is between 13 and 14\% (Fig. S2 $\dagger$ ). Cross calibration by external quantum efficiency (EQE) measurements confirmed the $J_{\mathrm{sc}}$ values recorded under the AM $1.5 \mathrm{G}$ solar spectrum with deviations within about $5 \%$ (see Fig. 1d). Although $J_{\mathrm{sc}}$ is similar for the oxo- $\mathrm{G}_{1}$ and reference devices, replacing the PEDOT:PSS with oxo- $\mathrm{G}_{1}$ significantly improves $V_{\text {oc }}$ and $\mathrm{FF}$. The increased $V_{\mathrm{oc}}$ can be dominantly attributed to the higher work function of oxo- $\mathrm{G}_{1}$ than that of PEDOT:PSS. The work function of oxo-G $\mathrm{G}_{1}$ and PEDOT:PSS determined with a Kelvin probe is found to be -5.2 and $-5.0 \mathrm{eV}$, respectively (Table 1). The relatively high FF of $77.7 \%$ attained for the oxo- $\mathrm{G}_{1}$-based devices can be partially attributed to the lower series resistance. The series resistance of $9.9 \Omega \mathrm{cm}^{2}$ is determined for the oxo- $\mathrm{G}_{1}$-based device from the $J-V$ characteristics in the dark, whilst $15.5 \Omega \mathrm{cm}^{2}$ are calculated for the PEDOT:PSS-based reference (Fig. 1e). Moreover, as can be seen from the atomic force microscopy images (Fig. 2), the perovskite layer on the PEDOT:PSS film exhibits a smaller grain size than that on oxo- $\mathrm{G}_{1}$, which may lead to the weak field dependence of the PEDOT:PSS-based device at the transition from the $4^{\text {th }}$ into the $3^{\text {rd }}$ quadrant. 
(a)

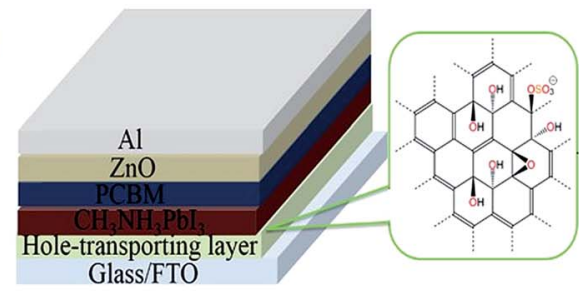

(c)

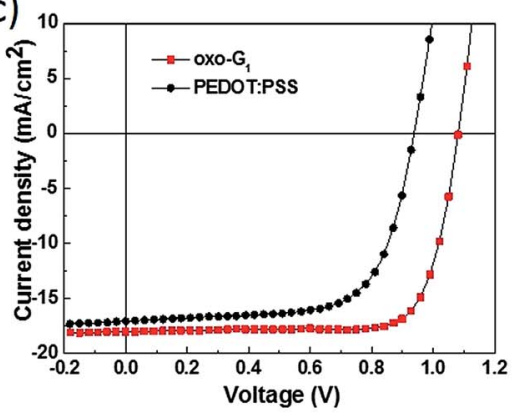

(e)

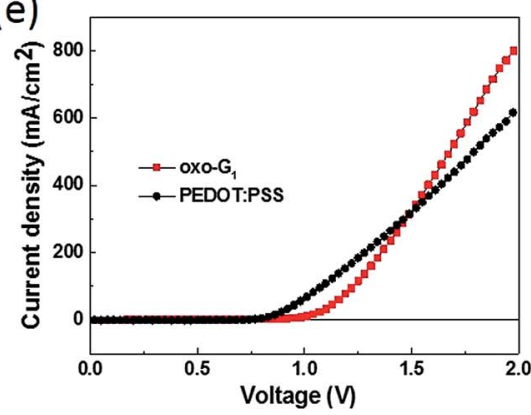

(b)

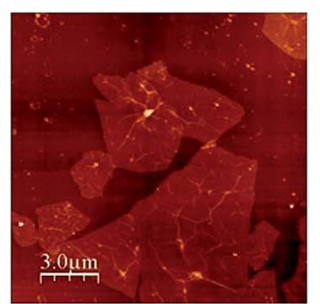

(d)

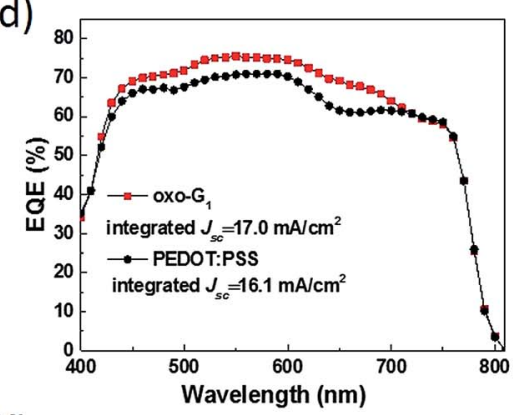

(f)

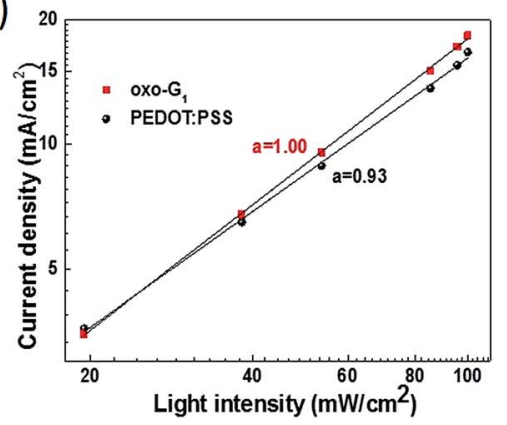

Fig. 1 (a) Schematic device structure of the perovskite solar cells with different electron-blocking layers, (b) a representative atomic force microscope (AFM) image of oxo- $\mathrm{G}_{1}$ on a $\mathrm{SiO}_{2} / \mathrm{Si}$ substrate, (c) $\mathrm{J}-\mathrm{V}$ and (d) $\mathrm{EQE}$ characteristics of oxo- $\mathrm{G}_{1} / \mathrm{CH}_{3} \mathrm{NH}_{3} \mathrm{Pbl} / \mathrm{PCBM}_{3} / \mathrm{ZnO} / \mathrm{Al}$ solar cells (red squares) and PEDOT:PSS/CH $\mathrm{CH}_{3} \mathrm{Nb}_{3} / \mathrm{PCBM} / \mathrm{ZnO} / \mathrm{Al}$ solar cells (black circles), (e) comparison of the dark J-V curves of PEDOT:PSS and oxo- $\mathrm{G}_{1}$ devices, and (f) short-circuit current as a function of the incident light intensity for different photovoltaic devices: oxo- $\mathrm{G}_{1} / \mathrm{CH}_{3} \mathrm{NH}_{3} \mathrm{~Pb} \mathrm{I}_{3} /$ PCBM/ZnO/Al solar cells (red squares) and PEDOT:PSS/CH ${ }_{3} \mathrm{NH}_{3} \mathrm{~Pb}{ }_{3} / \mathrm{PCBM} / \mathrm{ZnO} / \mathrm{Al}$ solar cells (black circles).

Table 1 Work function of PEDOT:PSS and OxO-G $\mathrm{G}_{1}$ measured with a Kelvin probe in air

\begin{tabular}{lll}
\hline & Work function $(\mathrm{eV})$ & Contact angle \\
\hline PEDOT:PSS & -5.0 & $18^{\circ}$ \\
Oxo-G $_{1}$ & -5.2 & $48^{\circ}$
\end{tabular}

Furthermore, light-intensity-dependent photocurrent measurements are performed to investigate the recombination mechanism of the devices (Fig. 1f). The relationship between $J_{\mathrm{sc}}$ and the incident light intensity $(I)$ typically follows a power law $\left(J_{\mathrm{sc}} \propto I^{\alpha}\right)$. The light intensity dependence of $J_{\mathrm{sc}}$ is plotted on a log-log scale in Fig. $1 \mathrm{f}$ for both types of devices and fitted to a power law. With an exponent $\alpha \approx 1$, the $2^{\text {nd }}$ order recombination is absent in oxo- $\mathrm{G}_{1}$-based devices under $J_{\mathrm{sc}}$ conditions. ${ }^{45}$ Interestingly, PEDOT:PSS-based devices show a small but distinct contribution from the $2^{\text {nd }}$ order recombination as evidenced by their lower $\alpha=0.93$.

The operational lifetime of the fabricated perovskite devices based on oxo- $\mathrm{G}_{1}$ and PEDOT:PSS interlayers is investigated with a home-built setup. Illumination is provided by LED lamps in order to prevent the negative influence of ultraviolet light on the light-soaking stability. In order to systematically evaluate the long-term stability of the fabricated devices, we detect the photovoltaic performance of unpackaged oxo- $\mathrm{G}_{1}$ and PEDOT:PSS devices under three different conditions: (a) storage in the dark and an ambient environment (Fig. 3a), (b) light soaking under 0.5 suns in a $\mathrm{N}_{2}$ atmosphere (Fig. $3 \mathrm{~b}$ ) and (c) light soaking under 0.5 suns in an environmental atmosphere (Fig. 3c). Oxo-G - $_{1}$-based devices show superior stability under all three conditions over their counterpart based on PEDOT:PSS. Oxo- $\mathrm{G}_{1}$-based solar cells are unusually stable under ambient conditions in the dark. Solar cells are stored for more than 1900 $\mathrm{h}$ under ambient conditions (a temperature of approximately $15-25^{\circ} \mathrm{C}$ and a relative humidity (RH) between 30 and $50 \%$ ) and retain $92 \%$ of their initial PCE (Fig. 3a). In contrast, PEDOT:PSSbased solar cells lose about $50 \%$ of their initial PCE already within about $400 \mathrm{~h}$. A similar trend is found for unpackaged cells operated in a $\mathrm{N}_{2}$ atmosphere under 0.5 suns (Fig. 3b). Oxo$\mathrm{G}_{1}$ solar cells exhibit higher photo-stability than that of the PEDOT:PSS-based solar cells, although the difference is much 

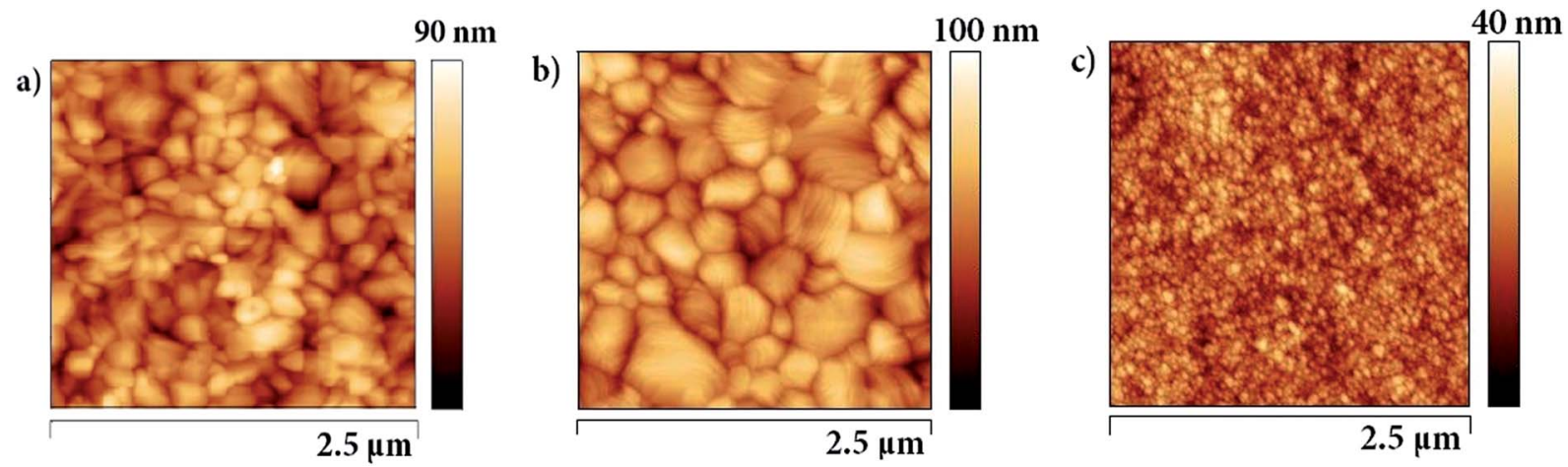

Fig. 2 AFM images of (a) perovskite grown on the PEDOT:PSS and (b) perovskite grown on the oxo- $G_{1}$; (c) ZnO on the oxo-G $/$ /perovskite/PCBM composite film.
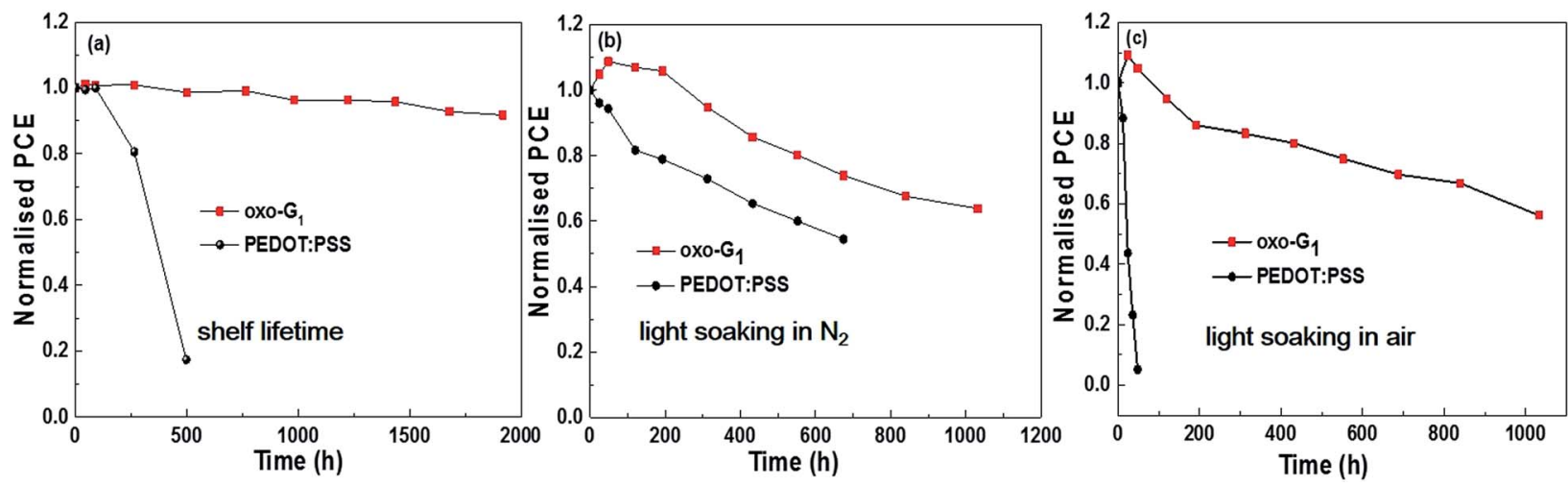

Fig. 3 Decline in PCE as a function of time for unsealed devices with oxo- $G_{1}$ compared to that of unsealed devices with PEDOT:PSS under three different conditions: (a) storage in the dark and an ambient environment, (b) light soaking under 0.5 suns in a $\mathrm{N}_{2}$ atmosphere, and (c) light soaking under 0.5 suns in an environmental atmosphere (all J-V characteristics were measured under AM 1.5 G illumination) (all the devices were held at open circuit).

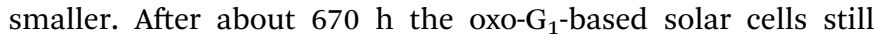
retain $74 \%$ of their initial PCE, while PEDOT:PSS-based devices retain only 54\% of their initial PCE after approximately $670 \mathrm{~h}$. The most significant discrepancy in the lifetime is, however, observed under ambient environmental conditions (a temperature of approximately $20-30{ }^{\circ} \mathrm{C}$ and a $\mathrm{RH}$ between 30 and $50 \%$ ) and illumination of approximately 0.5 sun equivalents provided by a white LED (Fig. 3c). Unsealed oxo-G ${ }_{1}$ devices retain $\sim 60 \%$ of their initial PCE after $1000 \mathrm{~h}$. In contrast, PEDOT:PSS devices lose more than $95 \%$ of their initial PCE within only $50 \mathrm{~h}$. This means the reference devices fail completely after $50 \mathrm{~h}$ and the oxo-G $\mathrm{G}_{1}$ devices did not yet show degradation. We summarize these measurements with the observation that unpackaged oxo$\mathrm{G}_{1}$-based perovskite solar cells show attractive environmental stability when compared to inverted architecture cells incorporating a PEDOT:PSS anode interfacial layer; it implies that oxo- $\mathrm{G}_{1}$ may act as a barrier inhibiting the ingress of moisture into the perovskite layer.

It seems obvious to correlate the attractive stability of oxo- $\mathrm{G}_{1}$ based devices with their enhanced hydrophobicity and potentially better moisture barrier properties as compared to those of PEDOT:PSS. As presented in Fig. $4 \mathrm{a}$ and b, oxo-G $\mathrm{G}_{1}$ has a larger contact angle of $48^{\circ}$ than that of PEDOT:PSS $\left(18^{\circ}\right)$, confirming that oxo- $\mathrm{G}_{1}$ is indeed more hydrophobic than PEDOT:PSS. To further understand the role of sulfated graphene oxide in blocking moisture ingress into the perovskite layer, FTO glasses coated with oxo- $\mathrm{G}_{1}$ or PEDOT:PSS are sealed to the open mouth of an aluminum cup filled with $\mathrm{CaCl}_{2}$ (Fig. S3†). A thin film of ultraviolet curable epoxy adhesive (Katiobond LP 655, Delo) is deposited onto the PEDOT:PSS or oxo-G - $_{1}$ coated FTO glass. Then, these cups are subjected to damp heat conditions in a climate chamber. Note that this method requires an adhesive with a water vapor diffusion constant being significantly below the one of the material of interest. We previously determined the water vapor diffusion constant $D$ for the adhesive Delo Katiobond LP 655 with approximately $1.1 \times 10^{-12} \mathrm{~cm}^{2} \mathrm{~s}^{-1}$ at 60 ${ }^{\circ} \mathrm{C} / 90 \% \mathrm{RH}$ and found that in excellent agreement with the WVTR value from the provider (WVTR $=6.1 \mathrm{~g} \mathrm{~m}^{-2} \mathrm{~d}^{-1}$ [http:// www.delo.de]). ${ }^{46}$ Feron et al. recently measured the diffusion coefficient of water in PEDOT:PSS and calculated a value of $D=$ $\sim 5.0 \times 10^{-10} \mathrm{~m}^{2} \mathrm{~s}^{-1}$, i.e., approximately two orders of magnitude larger than that of $D$ for our adhesive. ${ }^{47}$ It is therefore reasonable to expect a major contribution to water vapor ingress from the hole-extraction layer. Indeed, Fig. S4† confirms an at least 10-fold higher WVTR in PEDOT:PSS-based cups as compared to that of oxo- $\mathrm{G}_{1}$-based cups. 
(a)

(b)
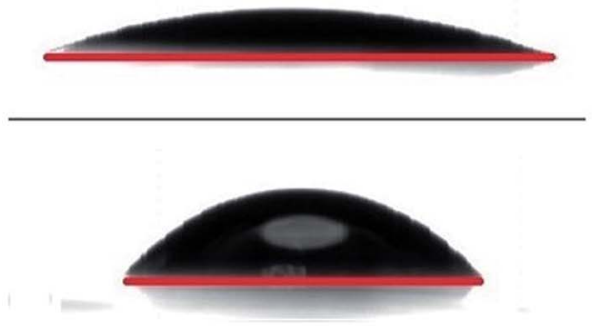

(d)

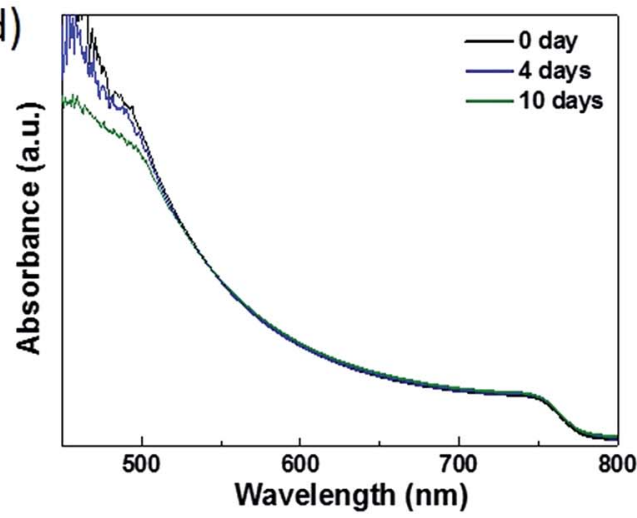

(c)
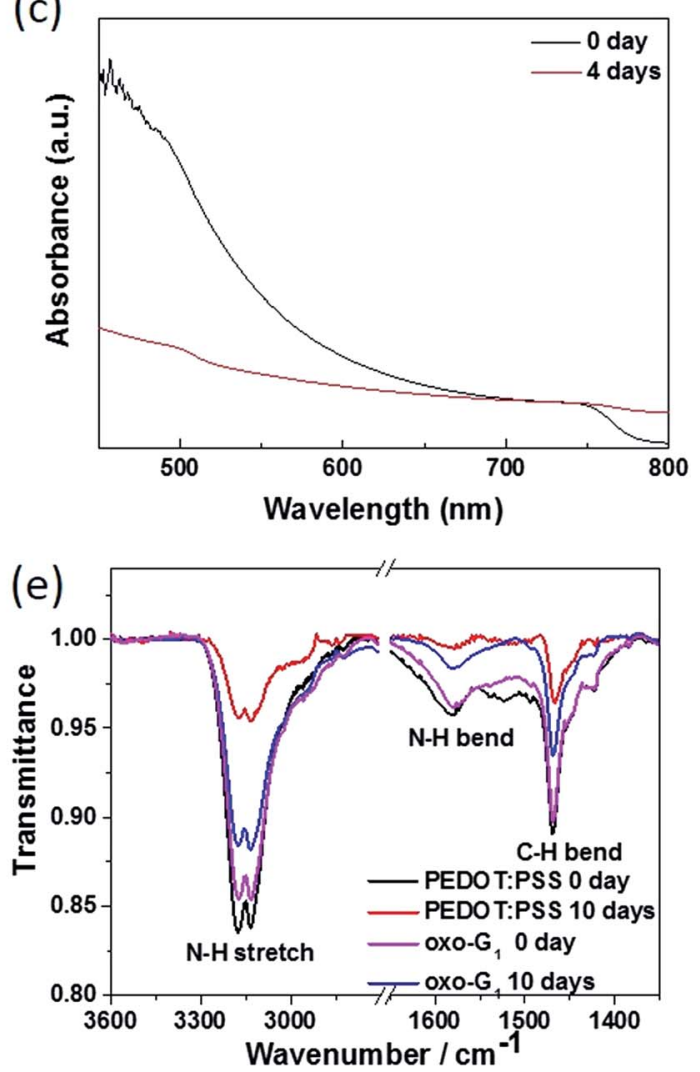

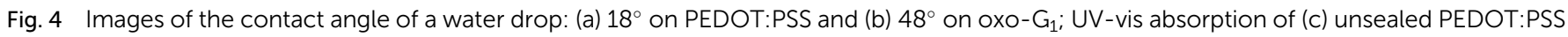
devices and (d) unsealed oxo- $G_{1}$ devices (light soaking under 0.5 suns in an environmental atmosphere); (e) ATR spectra of fresh and aged solar cells (light soaking under 0.5 suns in an environmental atmosphere).

Having elucidated that water vapor can indeed enter perovskite solar cells through the PEDOT:PSS layer, we next analyzed the degradation behavior of the respective devices under an ambient environment and light soaking by UV-vis and attenuated total reflectance-Fourier transform infrared (ATR-FTIR) spectroscopy. Fig. 4 reports a significant change in absorption for the PEDOT:PSS-based devices, while no or only negligible changes are observed for oxo- $\mathrm{G}_{1}$-based devices after 10 days under 0.5 suns and at a humidity of $30-50 \%$. We notice that all the features in Fig. $4 \mathrm{c}$ are in excellent correlation with the recent report by Kelly et al. ${ }^{8}$ who explained the three features of this spectrum by the formation of a mixture of perovskite, $\mathrm{PbI}_{2}$ and $\mathrm{PbI}_{x}$-based hydrate complexes. As reported by Venkatamaran et al., ion migration is induced and accelerated by visible light, which explains why perovskite devices under light soaking in an environmental atmosphere degraded faster than the corresponding devices stored in the dark and an ambient environment. ${ }^{48}$

ATR-FTIR spectroscopy is utilized to identify further degradation products on a molecular level. As depicted in Fig. 4e, the peak at $3200 \mathrm{~cm}^{-1}$ is attributed to the $\mathrm{N}-\mathrm{H}$ stretch vibration of the $\mathrm{CH}_{3} \mathrm{NH}_{3}$ - group. ${ }^{49}$ After being exposed to an ambient environment and light soaking for ten days, the peak for the $\mathrm{N}-\mathrm{H}$ stretch of the perovskite in the PEDOT:PSS devices dramatically declines, evidencing a serious loss of methyl amine in
PEDOT:PSS-based devices. As reported by Walsh et al., water can protonate excess iodide to form $\mathrm{HI}$ and deprotonate the methylammonium cation to produce methylamine. ${ }^{50}$ Both of these compounds are highly volatile. The evaporation of methylamine and $\mathrm{HI}$ will accelerate the rate of formation of the hydrated phase. In contrast, the signal of the $\mathrm{N}-\mathrm{H}$ stretch vibration of perovskite in oxo- $\mathrm{G}_{1}$-devices decreases only slightly (Fig. 4e), thus implying significantly reduced hydrolysis for oxo- $\mathrm{G}_{1}$-based devices.

\section{Conclusions}

In summary, we demonstrate surprisingly long operating lifetimes for unpackaged perovskite solar cells under continuous illumination with a white-light LED with a light intensity of $\sim 0.5$ suns and under ambient conditions. The environmental light-soaking stability of unpackaged inverted architecture perovskite solar cells is significantly enhanced by replacing PEDOT:PSS with oxo-G . Oxo-G $_{1}$ not only acts as an efficient hole-extraction layer, but more importantly, contributes to stabilizing perovskite solar cells by suppressing moisture ingress due to its hydrophobic nature compared to that of PEDOT:PSS. A champion efficiency of up to $15.2 \%$ has been obtained using a graphene derivative layer oxo- $\mathrm{G}_{1}$ and unpackaged oxo- $\mathrm{G}_{1}$ solar cells retain $\sim 60 \%$ of their initial 
performance after $1000 \mathrm{~h}$ of light soaking. The findings demonstrated in this work highlight the importance of designing hydrophobic interfacial layers with low WVTR as a crucial development towards more stable perovskite solar cells.

\section{Acknowledgements}

H. C. and Y. H. contributed equally to this work. The authors would like to acknowledge the support of the Cluster of Excellence "Engineering of Advanced Materials (EAM)", the DFG research training group GRK 1896 at Erlangen University and from the Joint Project Helmholtz-Institute Erlangen Nürnberg (HI-ERN) under the project number DBF01253, Energy Campus Nuremberg (EnCN, Solarfactory), DFG research training group GRK 1896, Graduate School Molecular Science, and the Erlangen Graduate School in Advanced Optical Technologies (SAOT) at the University of ErlangenNuremberg. This work has been partially supported by the China Scholarship Council (CSC). C. J. B. would like to thank the financial support from the "Aufbruch Bayern" initiative of the state of Bavaria (EnCN and the solar factory of the future), the "Solar factory of the future" with the Energy Campus Nürnberg (EnCN) and the Bavarian Initiative "Solar Technologies go Hybrid" (SolTech). S. E. acknowledges the DFG for financing by grand no. EI938/3-1 and SFB953 for supporting the research.

\section{Notes and references}

1 W. S. Yang, J. H. Noh, N. J. Jeon, Y. C. Kim, S. Ryu, J. Seo and S. I. Seok, Science, 2015, 348, 1234-1237.

2 M. L. Cai, V. T. Tiong, T. Hreid, J. Bell and H. X. Wang, J. Mater. Chem. A, 2015, 3, 2784-2793.

3 H. W. Chen, X. Pan, W. Q. Liu, M. L. Cai, D. X. Kou, Z. P. Huo, X. Q. Fang and S. Y. Dai, Chem. Commun., 2013, 49, 72777279.

4 T. Leijtens, G. E. Eperon, N. K. Noel, S. N. Habisreutinger, A. Petrozza and H. J. Snaith, Adv. Energy Mater., 2015, 5, 1500963.

5 F. Guo, H. Azimi, Y. Hou, T. Przybilla, M. Y. Hu, C. Bronnbauer, S. Langner, E. Spiecker, K. Forberich and C. J. Brabec, Nanoscale, 2015, 7, 1642-1649.

6 Y. G. Rong, L. F. Liu, A. Y. Mei, X. Li and H. W. Han, Adv. Energy Mater., 2015, 5, 1501066.

7 J. A. Christians, P. A. M. Herrera and P. V. Kamat, J. Am. Chem. Soc., 2015, 137, 1530-1538.

8 J. L. Yang, B. D. Siempelkamp, D. Y. Liu and T. L. Kelly, ACS Nano, 2015, 9, 1955-1963.

9 Q. Jiang, D. Rebollar, J. Gong, E. L. Piacentino, C. Zheng and T. Xu, Angew. Chem., Int. Ed., 2015, 54, 11006.

10 I. C. Smith, E. T. Hoke, D. Solis-Ibarra, M. D. McGehee and H. I. Karunadasa, Angew. Chem., Int. Ed., 2014, 53, 1123211235.

11 Z. Li, M. J. Yang, J. S. Park, S. H. Wei, J. J. Berry and K. Zhu, Chem. Mater., 2016, 28, 284-292.
12 X. Li, M. I. Dar, C. Y. Yi, J. S. Luo, M. Tschumi, S. M. Zakeeruddin, M. K. Nazeeruddin, H. W. Han and M. Gratzel, Nat. Chem., 2015, 7, 703-711.

13 S. N. Habisreutinger, T. Leijtens, G. E. Eperon, S. D. Stranks, R. J. Nicholas and H. J. Snaith, Nano Lett., 2014, 14, 55615568.

14 I. Hwang, I. Jeong, J. Lee, M. J. Ko and K. Yong, ACS Appl. Mater. Interfaces, 2015, 7, 17330-17336.

15 A. Y. Mei, X. Li, L. F. Liu, Z. L. Ku, T. F. Liu, Y. G. Rong, M. Xu, M. Hu, J. Z. Chen, Y. Yang, M. Gratzel and H. W. Han, Science, 2014, 345, 295-298.

16 H. Y. Wei, J. Y. Xiao, Y. Y. Yang, S. T. Lv, J. J. Shi, X. Xu, J. Dong, Y. H. Luo, D. M. Li and Q. B. Meng, Carbon, 2015, 93, 861-868.

17 X. Li, M. Tschumi, H. W. Han, S. S. Babkair, R. A. Alzubaydi, A. A. Ansari, S. S. Habib, M. K. Nazeeruddin, S. M. Zakeeruddin and M. Gratzel, Energy Technol., 2015, 3, 551-555.

18 L. Z. Zhu, Z. P. Shao, J. J. Ye, X. H. Zhang, X. Pan and S. Y. Dai, Chem. Commun., 2016, 52, 970-973.

19 T. Leijtens, G. E. Eperon, S. Pathak, A. Abate, M. M. Lee and H. J. Snaith, Nat. Commun., 2013, 4, 2885.

20 Q. F. Xue, Z. C. Hu, J. Liu, J. H. Lin, C. Sun, Z. M. Chen, C. H. Duan, J. Wang, C. Liao, W. M. Lau, F. Huang, H. L. Yip and Y. Cao, J. Mater. Chem. A, 2014, 2, 19598-19603. 21 M. Lv, J. Zhu, Y. Huang, Y. Li, Z. P. Shao, Y. F. Xu and S. Y. Dai, ACS Appl. Mater. Interfaces, 2015, 7, 17482-17488.

22 S. E. Ela, H. W. Chen, A. Kratzer, A. Hirsch and C. J. Brabec, New J. Chem., 2016, 2829-2834.

23 T. Salim, S. Y. Sun, Y. Abe, A. Krishna, A. C. Grimsdale and Y. M. Lam, J. Mater. Chem. A, 2015, 3, 8943-8969.

24 W. B. Yan, Y. L. Li, Y. Li, S. Y. Ye, Z. W. Liu, S. F. Wang, Z. Q. Bian and C. H. Huang, Nano Res., 2015, 8, 2474-2480. 25 C. Bi, Q. Wang, Y. C. Shao, Y. B. Yuan, Z. G. Xiao and J. S. Huang, Nat. Commun., 2015, 6, 7747.

26 H. Zhang, H. Azimi, Y. Hou, T. Ameri, T. Przybilla, E. Spiecker, M. Kraft, U. Scherf and C. J. Brabec, Chem. Mater., 2014, 26, 5190-5193.

27 Y. Hou, H. Zhang, W. Chen, S. Chen, C. O. R. Quiroz, H. Azimi, A. Osvet, G. J. Matt, E. Zeira, J. Seuring, N. Kausch-Busies, W. Lovenich and C. J. Brabec, Adv. Energy Mater., 2015, 5, 1500543.

28 J. H. Kim, P. W. Liang, S. T. Williams, N. Cho, C. C. Chueh, M. S. Glaz, D. S. Ginger and A. K. Y. Jen, Adv. Mater., 2015, 27, 695-701.

29 X. B. Xu, Z. H. Liu, Z. X. Zuo, M. Zhang, Z. X. Zhao, Y. Shen, H. P. Zhou, Q. Chen, Y. Yang and M. K. Wang, Nano Lett., 2015, 15, 2402-2408.

30 S. Y. Ye, W. H. Sun, Y. L. Li, W. B. Yan, H. T. Peng, Z. Q. Bian, Z. W. Liu and C. H. Huang, Nano Lett., 2015, 15, 3723-3728.

31 J. H. Park, J. Seo, S. Park, S. S. Shin, Y. C. Kim, N. J. Jeon, H. W. Shin, T. K. Ahn, J. H. Noh, S. C. Yoon, C. S. Hwang and S. I. Seok, Adv. Mater., 2015, 27, 4013-4019.

32 J. S. Yeo, R. Kang, S. Lee, Y. J. Jeon, N. Myoung, C. L. Lee, D. Y. Kim, J. M. Yun, Y. H. Seo, S. S. Kim and S. I. Na, Nano Energy, 2015, 12, 96-104. 
33 Z. W. Wu, S. Bai, J. Xiang, Z. C. Yuan, Y. G. Yang, W. Cui, X. Y. Gao, Z. Liu, Y. Z. Jin and B. Q. Sun, Nanoscale, 2014, 6, 10505-10510.

34 J. B. You, L. Meng, T. B. Song, T. F. Guo, Y. Yang, W. H. Chang, Z. R. Hong, H. J. Chen, H. P. Zhou, Q. Chen, Y. S. Liu, N. De Marco and Y. Yang, Nat. Nanotechnol., 2016, 11, 75-81.

35 W. Chen, Y. Z. Wu, Y. F. Yue, J. Liu, W. J. Zhang, X. D. Yang, H. Chen, E. B. Bi, I. Ashraful, M. Gratzel and L. Y. Han, Science, 2015, 350, 944-948.

36 S. Eigler and A. Hirsch, Angew. Chem., Int. Ed., 2014, 53, 7720-7738.

37 S. Eigler, M. Enzelberger-Heim, S. Grimm, P. Hofmann, W. Kroener, A. Geworski, C. Dotzer, M. Rockert, J. Xiao, C. Papp, O. Lytken, H. P. Steinruck, P. Muller and A. Hirsch, Adv. Mater., 2013, 25, 3583-3587.

38 S. Eigler, C. Dotzer, F. Hof, W. Bauer and A. Hirsch, Chem.Eur. J., 2013, 19, 9490-9496.

39 Z. X. Wang, S. Eigler, Y. Ishii, Y. C. Hu, C. Papp, O. Lytken, H. P. Steinruck and M. Halik, J. Mater. Chem. C, 2015, 3, 8595-8604.

40 S. Eigler, C. Dotzer, F. Hof, W. Bauer and A. Hirsch, Chem.Eur. J., 2013, 19, 9490-9496.
41 S. Eigler, F. Hof, M. Enzelberger-Heim, S. Grimm, P. Müller and A. Hirsch, J. Phys. Chem. C, 2014, 118, 7698-7704.

42 S. Eigler, S. Grimm, F. Hof and A. Hirsch, J. Mater. Chem. A, 2013, 1, 11559-11562.

43 C. E. Halbig, T. J. Nacken, J. Walter, C. Damm, S. Eigler and W. Peukert, Carbon, 2016, 96, 897-903.

44 L. G. Cancado, A. Jorio, E. H. Ferreira, F. Stavale, C. A. Achete, R. B. Capaz, M. V. Moutinho, A. Lombardo, T. S. Kulmala and A. C. Ferrari, Nano Lett., 2011, 11, 3190-3196.

45 S. R. Cowan, A. Roy and A. J. Heeger, Phys. Rev. B: Condens. Matter Mater. Phys., 2010, 82, 245207.

46 J. Adams, M. Salvador, L. Lucera, S. Langner, G. D. Spyropoulos, F. W. Fecher, M. M. Voigt, S. A. Dowland, A. Osvet, H. J. Egelhaaf and C. J. Brabec, Adv. Energy Mater., 2015, 5, 1501065.

47 K. Feron, T. J. Nagle, L. J. Rozanski, B. B. Gong and C. J. Fell, Sol. Energy Mater. Sol. Cells, 2013, 109, 169-177.

48 M. Bag, L. A. Renna, R. Y. Adhikari, S. Karak, F. Liu, P. M. Lahti, T. P. Russell, M. T. Tuominen and D. Venkataraman, J. Am. Chem. Soc., 2015, 137, 13130-13137.

49 N. J. Jeon, J. H. Noh, Y. C. Kim, W. S. Yang, S. Ryu and S. Il Seol, Nat. Mater., 2014, 13, 897-903.

50 J. M. Frost, K. T. Butler, F. Brivio, C. H. Hendon, M. van Schilfgaarde and A. Walsh, Nano Lett., 2014, 14, 2584-2590. 